\title{
Combination of waveforms in modern spinal cord stimulation
}

\author{
Piedade G. $S^{1} \cdot{\text { Gillner } S .^{2} \cdot \text { Slotty P. J. }}^{2} \cdot$ Vesper $\mathrm{J}^{2}$ \\ Received: 12 September 2021 / Accepted: 28 December 2021 / Published online: 5 January 2022 \\ (c) The Author(s) 2022
}

\begin{abstract}
Background After the surge of burst stimulation, different waveforms were developed to optimize results in spinal cord stimulation. Studies have shown higher responder rates for multiwave therapy, but since the launch of such multiwave systems, little is known about the patients' preference regarding waveforms in the long-term follow-up. No study connected particular waveforms to specific pain etiologies or required stimulation parameters so far.

Method Thirty-four patients with refractory chronic neuropathic pain were treated with spinal cord stimulation systems providing multiwave therapy between September 2018 and October 2019. Patients with a follow-up of at least 6 months were selected; 10 subjects were excluded due to revision surgery, infection, and loss to follow-up. Data regarding pain intensity and preferred waveform for the trial, the implantation, 3-month and 6-month follow-up were recorded.

Results During the trial phase, 10 patients (43.5\%) achieved significant pain relief using tonic stimulation, 5 using burst (21.7\%), 3 using microburst (13.0\%), and 4 using a combination of tonic and microburst (17.4\%). One single patient preferred Contour stimulation during the trial. After 3 months, 6 patients preferred microburst (25\%), 6 preferred tonic $(25 \%)$, 5 used a combination of tonic and microburst (20.8\%), and 5 patients used burst (20.8\%). After 6 months, similar results were obtained. Contour and Whisper were used in complex cases failing to other waveforms.

Conclusions Tonic stimulation, isolated or in combination, remains an important component in spinal cord stimulation, being used by almost half of the patients. Over time, the usage of microburst increased considerably. Whisper and Contour, although battery-consuming, are good salvage options in complex cases.
\end{abstract}

Keywords Spinal cord stimulation · Waveform · Combination therapy $\cdot$ Neuropathic pain

\section{Abbreviations}

SCS Spinal cord stimulation

VAS Visual analog scale

IRB Institutional review board

IPG Implantable pulse generator
This article is part of the Topical Collection on Functional Neurosurgery - Pain

Piedade G. S

guilherme.santospiedade@med.uni-duesseldorf.de

1 Department of Neurosurgery, Heinrich-Heine-Universität Düsseldorf, Moorenstr. 5, 40225 Düsseldorf, Germany

2 Department of Functional Neurosurgery and Stereotaxy, Heinrich-Heine-Universität Düsseldorf, Düsseldorf, Germany

\section{Introduction}

The field of spinal cord stimulation (SCS) developed in recent years with new waveforms targeting different needs in the therapy of neuropathic pain. Tonic stimulation $(10-150 \mathrm{~Hz})$ was the very first to be developed and provides mostly paresthesia in the stimulated area, which is very useful when evaluating the coverage of the painful area during the first programming session. Burst stimulation was later developed and its first form consisted of five stimulus bursts, classically with an intraburst frequency of $500 \mathrm{~Hz}$, delivered with a frequency of $40 \mathrm{~Hz}$ under constant amplitude [3]. It provided significant pain relief to patients previously using classic tonic stimulation [2]. After the surge of burst stimulation that made a paresthesia-free stimulation possible, alternatives such as microburst, Whisper, and Contour appeared and gained relevance in the neuromodulation of the spinal cord (Table 1) [1]. Commercially available systems were developed to provide multiwave therapy-some of them even simultaneously [6]. Systems that allow patients 
Table 1 Waveforms provided by the tested devices

\begin{tabular}{ll}
\hline & Definition \\
\hline Tonic & Regular stimuli generally applied with a frequency of 10 to $150 \mathrm{~Hz}$, amplitude up to $25 \mathrm{~Hz}$ \\
Burst & Intermittent packets of burst stimuli with $2-7$ pulses per packet, interburst frequency of $40 \mathrm{~Hz}$ and pulse widths up to \\
& $1000 \mu \mathrm{s}$, amplitude at $60 \%$ of the perception threshold \\
Microburst & Customized stimulation with 2-1000 pulses per packet, $1-80 \mathrm{~Hz}$ interburst frequency, and up to $1200 \mathrm{~Hz}$ intraburst frequency \\
Contour & Algorithm that shapes the stimulation field over multiple vertebral levels to the spinal anatomy and lead position \\
Whisper & High-frequency tonic stimulation between 1000 and $1200 \mathrm{~Hz}$, amplitude at $60 \%$ of the perception threshold \\
\hline
\end{tabular}

to choose among multiple waveforms were reported to have high responder rates even in previously implanted patients that failed to trials with high-dose SCS [4]. Since the launch of such multiwave systems, little is known about the patients' preference regarding waveforms in the long-term follow-up. We aim to report our experience with the programming of spinal cord stimulators in the context of multiwave therapy, identify the prevalence of different waveforms over time, and critically discuss the importance of each of them in the treatment of chronic pain.

\section{Methods and materials}

Patients with chronic neuropathic pain that were treated with spinal cord stimulation systems providing multiwave therapy between September 2018 and October 2019 in our center were preselected; those achieving at least 6 months of follow-up were included in the study. Data regarding pain intensity and waveform in use for the trial, the implantation, and the follow-up appointments were collected. Pain intensity was assessed with the visual analog scale (VAS).

Implanted systems were Spectra Wavewriter ${ }^{\mathrm{TM}}$ and Precision Montage ${ }^{\mathrm{TM}}$, both manufactured by Boston Scientific Corporation (Marlborough, MA, USA). The first system was used in 13 patients and is the only one to allow simultaneous treatment with two different waveforms using different electrodes. In both systems, the percentage of electric current running through each individual electrode can be controlled.

This study was approved by the local IRB (2020-905). We used descriptive statistics in this study.

\section{Results}

A total of 34 patients were treated with a spinal cord stimulation system providing multiwave therapy; 10 subjects however did not achieve 6 months of follow-up due to revision surgery, infection, and loss to follow-up and were therefore excluded from the analysis. We analyzed a study pool of 24 patients. Twenty-three patients were submitted to a trial of spinal cord stimulation; in one case, an older IPG was substituted by a device with multiwave therapy. A trial with temporary lead in an out-patient setting was done in 14 patients; in these cases, the trial lasted for 14 days. The remaining 9 patients were submitted to a trial with permanent lead; the trial phase lasted for a maximum of 14 days but could be interrupted earlier for implantation of the IPG. Test of each waveform during the trial lasted for approximately 4 days each. Patients under multiwave therapy had a mean age of 61.8 years at the implantation of the pulse generator (IPG) and were predominantly female (66.7\%); mean follow-up of 6.8 months was seen (Table 2). The time period between trial and implant was on average 19.3 days. Failed back surgery syndrome responded for 15 of the indications for spinal cord stimulation $(62.5 \%)$; mean pain intensity at the baseline was 8.1. A successful trial stimulation was obtained in 10 patients with tonic stimulation $(43.5 \%)$, followed by burst $(5,21.7 \%)$, tonic and microburst $(4,17.3 \%)$, microburst $(3,13.0 \%)$, and Contour (1, 4.3\%). Patient 13 was already under SCS with another system; in a revision surgery, the system was changed without a previous trial using multiwave therapy. After implantation of the IPG, patients were discharged with similar stimulation parameters. Tonic stimulation was rejected by three patients and a good response was seen in 7 cases $(29.2 \%)$; microburst was chosen by two more individuals and was chosen by 5 discharged patients (20.1\%). One single patient was discharged alternating frequently between tonic and burst; the IPG in this case could not provide simultaneous stimulation with both waveforms.

After 3 months of follow-up, mean VAS decreased to 3.9 , a mean reduction of $51.9 \%$ in pain intensity. Overall, 15 patients $(62.5 \%)$ had a significant pain relief of at least $50 \%$. Tonic and microburst were the most used waveforms, each preferred by 6 patients (25\%). Burst and the combination of tonic and microburst were used by 5 patients each (20.8\%); the combinations of tonic and burst and of burst and microburst were the case of one patient each (4.2\%).

At 6 months follow-up, mean VAS stabilized at 3.9 and 16 patients $(66.7 \%)$ achieved pain relief of at least $50 \%$. Tonic stimulation, burst, and the combination of tonic and microburst were preferred by 5 patients each $(20.8 \%)$ and were followed by microburst alone $(4,16.7 \%)$. Whisper was 
Table 2 Pain intensity and preferred waveform over time

\begin{tabular}{|c|c|c|c|c|c|c|c|c|c|c|c|c|c|}
\hline & \multirow[t]{2}{*}{ Age } & \multirow[t]{2}{*}{ Sex } & \multirow[t]{2}{*}{ Pain etiology } & \multirow[t]{2}{*}{ Lead level } & \multicolumn{2}{|c|}{ Baseline } & \multirow{2}{*}{$\begin{array}{l}\text { Implanta- } \\
\text { tion Wave- } \\
\text { form }\end{array}$} & \multicolumn{2}{|c|}{3 months f/u } & \multicolumn{2}{|c|}{6 months $\mathrm{f} / \mathrm{u}$} & \multicolumn{2}{|c|}{12 months $\mathrm{f} / \mathrm{u}$} \\
\hline & & & & & VAS & Waveform & & VAS & Waveform & VAS & Waveform & VAS & Waveform \\
\hline 1 & 51 & $\mathrm{~F}$ & Low back pain & T9 & 7 & Tonic & Tonic & 3 & MB & 0 & Tonic/MB & & \\
\hline 2 & 52 & M & FBSS & T9 and T7 & 9 & Tonic/MB & Tonic/MB & 7 & Tonic/MB & 3 & Tonic/MB & 2 & Tonic/MB \\
\hline 3 & 71 & M & Post-myelitis & $\mathrm{C} 5$ & 8 & Tonic/MB & Tonic/MB & 5 & Tonic/MB & 3 & Whisper & & \\
\hline 4 & 58 & M & FBSS & T9 & 8 & MB & MB & 3 & MB & 3 & Tonic/MB & & \\
\hline 5 & 81 & $\mathrm{~F}$ & FBSS & $\mathrm{T} 8$ & 8 & $\mathrm{MB}$ & MB & 8 & Tonic/MB & 4 & Contour & & \\
\hline 6 & 78 & $\mathrm{~F}$ & FBSS & T9 & 8 & Contour & Contour & 8 & MB & 8 & MB & & \\
\hline 7 & 77 & $\mathrm{~F}$ & Sciatica & T9 & 8 & Tonic/MB & MB & 2 & MB & 4 & MB & & \\
\hline 8 & 84 & $\mathrm{~F}$ & Sciatica & T9 & 9 & Tonic & Tonic & 5 & Tonic & 4 & Tonic & & \\
\hline 9 & 70 & $\mathrm{~F}$ & FBSS & $\mathrm{T} 8$ & 8 & Burst & Tonic/MB & 4 & Tonic/MB & 8 & Tonic/MB & & \\
\hline 10 & 67 & $\mathrm{~F}$ & FBSS & $\mathrm{T} 8$ & 8 & Tonic & MB & 1 & MB & 1 & Tonic/MB & & \\
\hline 11 & 70 & $\mathrm{~F}$ & FBSS & $\mathrm{T} 7$ & 9 & MB & MB & 3 & Burst/MB & 5 & Burst/MB & & \\
\hline 12 & 71 & $\mathrm{~F}$ & FBSS & $\mathrm{T} 8$ & 9 & Tonic/MB & Tonic/MB & 2 & Tonic/MB & 2 & MB & & \\
\hline 13 & 80 & $\mathrm{~F}$ & FBSS & T9 & 8 & - & MB & 9 & MB & 8 & MB & & \\
\hline 14 & 59 & M & Sciatica & T9 & 7 & Tonic & Tonic & 3 & Tonic & 7 & Tonic & & \\
\hline 15 & 48 & $\mathrm{~F}$ & Sciatica & T9 & 6 & Burst & Burst & 4 & Burst & 6 & Burst & 5 & Burst \\
\hline 16 & 58 & M & FBSS & $\mathrm{T} 8$ & 8 & Tonic & Tonic & 2 & Tonic & 4 & Burst & & \\
\hline 17 & 47 & M & Peripheral neuropathy & $\mathrm{T} 10$ & 9 & Burst & Burst & 3 & Tonic & 3 & Tonic & & \\
\hline 18 & 51 & M & Post-traumatic & $\mathrm{T} 8$ & 9 & Burst & Burst & 2 & Burst & 2 & Burst & & \\
\hline 19 & 39 & $\mathrm{~F}$ & FBSS & $\mathrm{T} 8$ & 9 & Tonic & Burst & 0 & Burst & 7 & Tonic/burst & & \\
\hline 20 & 61 & $\mathrm{~F}$ & FBSS & $\mathrm{T} 7$ & 8 & Tonic & Tonic & 3 & Tonic & 3 & Burst & & \\
\hline 21 & 41 & $\mathrm{~F}$ & FBSS & $\mathrm{C} 4$ & 6 & Tonic & Tonic/burst & 4 & Tonic/burst & 2 & Tonic & & \\
\hline 22 & 57 & M & FBSS & $\mathrm{T} 8$ & 8 & Tonic & Tonic & 4 & Tonic & 0 & Tonic & & \\
\hline 23 & 59 & $\mathrm{~F}$ & FBSS & $\mathrm{C} 5$ & 7 & Tonic & Tonic & 6 & Burst & 4 & Whisper & & \\
\hline 24 & 53 & $\mathrm{~F}$ & Sciatica & $\mathrm{T} 8$ & 10 & Burst & Burst & 3 & Burst & 3 & Burst & 6 & Burst \\
\hline
\end{tabular}

Patients 1-13 were implanted with Spectra WaveWriter ${ }^{\mathrm{TM}}$ and could choose two different waveforms to act simultaneously; patients 14-24 were implanted with Precision Montage ${ }^{\mathrm{TM}}$. Lead level indicates the vertebral level of the tip of the lead. Subjects are presented in aleatory order. FBSS failed back surgery syndrome, $M B$ microburst

Table 3 Prevalence of waveforms over time

\begin{tabular}{lllll}
\hline & Trial & Implantation & 3 months f/u & 6 months f/u \\
\hline Tonic & $43.5 \%$ & $29.2 \%$ & $25.0 \%$ & $20.8 \%$ \\
Burst & $21.7 \%$ & $20.8 \%$ & $20.8 \%$ & $20.8 \%$ \\
Microburst & $13.0 \%$ & $20.1 \%$ & $25.0 \%$ & $16.7 \%$ \\
Contour & $4.3 \%$ & $4.2 \%$ & $0 \%$ & $4.2 \%$ \\
Whisper & $0 \%$ & $0 \%$ & $0 \%$ & $8.3 \%$ \\
Tonic + micro- & $17.3 \%$ & $16.7 \%$ & $20.8 \%$ & $20.8 \%$ \\
$\quad$ burst & & & & \\
$\begin{array}{l}\text { Tonic + burst } \\
\text { Burst + micro- }\end{array}$ & $0 \%$ & $4.2 \%$ & $4.2 \%$ & $4.2 \%$ \\
$\quad$ burst & $0 \%$ & $0 \%$ & $4.2 \%$ & $4.2 \%$ \\
\hline
\end{tabular}

used by 2 patients $(8.3 \%)$; Contour and the combinations of burst with microburst and of burst with tonic were preferred by one patient each $(4.2 \%)$.

Table 3 gives a better overview of the prevalence of different waveforms over time. Isolated tonic stimulation was the most frequent waveform in successful trials, but lost half of its patients for other waveforms. Burst and microburst kept roughly a fifth of the patients during the entire duration of the observation period. When combinations are also considered, however, tonic stimulation was an important component of the therapy in 14 patients $(60.8 \%)$ and at 6 months follow-up still was used by 11 (45.8\%), being the most used waveform in this study. Microburst initially was used by 7 individuals (30.3\%), progressed to 12 at 3 months follow-up (50\%) and at the end responded for 10 study subjects $(41.7 \%)$. Burst was rarely used in combination with other waveforms; its prevalence grew up from $5(21.7 \%)$ to 7 subjects $(29.2 \%)$ at 6 months follow-up.

\section{Discussion}

This study observed the phenomenon of a decrease in the prevalence of tonic stimulation alone over time, favoring burst, microburst, or a combination. Many patients sense 
stimulation-induced paresthesia of tonic stimulation as a comfortable feeling. If there is a good coverage and patients do not need higher current intensities, many patients remain using exclusively tonic. In the case, however, that sufficient pain relief can only be achieved using higher current intensities; subperception therapies are generally preferred, such as burst stimulation and microburst. Both waveforms allow a higher tissue activation without the side effects of tonic stimulation using high amplitudes. The same occurs in the case of insufficient coverage of the painful area, when higher amplitudes try to compensate the pain of the uncovered region. That is possibly the reason why combinations between tonic and burst or microburst are frequent during the initial programming and get even more frequent over time.

When considered together, burst stimulation and microburst were used by 12 patients during the trial (52\%) and after 6 months were a component of the therapy in 17 of them (70.9\%). An alternative to burst that reduces battery consumption is microburst, with an intraburst frequency of $450 \mathrm{~Hz}$. Microdosing burst stimulation with alternation of ON and OFF periods was also a successful strategy [10].

In this study, two patients with cervical leads used Whisper stimulation at a frequency of $1 \mathrm{kHz}$ after tonic and burst stimulation failed to provide sufficient pain relief. One subject achieved significant pain relief; the other one had a reduction of $42.8 \%$ in pain intensity. High-frequency spinal cord stimulation was initially tested for $10 \mathrm{kHz}$ with superiority to conventional tonic stimulation in the SENZA trial [5]. Equivalent pain relief, however, was obtained using $1 \mathrm{kHz}$ in the PROCO trial, which reduced battery consumption [9]. The Whisper trial tested frequencies up to $1.2 \mathrm{kHz}$ in previously implanted patients and, when the patients were given the choice, increased pain relief was achieved [7]. High-frequency stimulation has been used particularly in the case of cervical leads with good outcomes [8].

Contour was preferred by only two patients in the study at different times. It is a waveform that shapes the stimulation field to the patients' anatomy, activating uniformly the dorsal columns despite variabilities in the lead position. Contour is now programmed with $200 \mathrm{~Hz}$ and its efficacy has been particularly tested with leads with $1 \mathrm{~mm}$ edge-to-edge spacing between electrodes. It is however possible to program it with leads with higher spacing. Contour is a good option in minor lead migration.

This study has the weakness of being retrospective, even considering the high quality of each case's documentation. If paresthesia coverage and stimulation parameters had been prospectively assessed, more conclusions could have been drawn about the reasons for the use of a specific waveform in each case. This study has however the strength of depicting the preference for waveforms or a combination of them with a high external validity and provides valuable information for the management of stimulation parameters in the context of multiwave therapy in the mid and long term.

\section{Conclusion}

Tonic stimulation, isolated or in combination with other waveforms, is still a very important component of modern SCS. Burst stimulation and microburst represent effective paresthesia-free alternatives. Whisper and Contour, although batteryconsuming, are good salvage options in complex cases.

Author contribution GSP and JV conceived the idea; JV, GSP, PJS, and SG performed the procedures and follow-ups; GSP and PJS developed the project; GSP wrote the manuscript with input from all authors. All authors approved the final version of the manuscript.

Funding Open Access funding enabled and organized by Projekt DEAL. Parts of the findings in this paper have been presented at the 2020 Meeting for Pain of the German Society of Neurosurgery.

\section{Declarations}

Ethics approval All procedures performed in studies involving human participants were in accordance with the ethical standards of the ethics committee of the Medical Faculty of the Heinrich-Heine-University Düsseldorf and with the 1964 Helsinki declaration and its later amendments or comparable ethical standards. For this type of study, formal consent was not required.

Conflict of interest PJS and JV received travel expense reimbursement and speaker honoraria from Abbott. JV is paid consultant of Abbott. GSP certifies that he has no affiliations with or involvement in any organization or entity with any financial or non-financial interest in the subject matter or materials discussed in this manuscript.

Open Access This article is licensed under a Creative Commons Attribution 4.0 International License, which permits use, sharing, adaptation, distribution and reproduction in any medium or format, as long as you give appropriate credit to the original author(s) and the source, provide a link to the Creative Commons licence, and indicate if changes were made. The images or other third party material in this article are included in the article's Creative Commons licence, unless indicated otherwise in a credit line to the material. If material is not included in the article's Creative Commons licence and your intended use is not permitted by statutory regulation or exceeds the permitted use, you will need to obtain permission directly from the copyright holder. To view a copy of this licence, visit http://creativecommons.org/licenses/by/4.0/.

\section{References}

1. Billot M, Naiditch N, Brandet C et al (2020) Comparison of conventional, burst and high-frequency spinal cord stimulation on pain relief in refractory failed back surgery syndrome patients: study protocol for a prospective randomized double-blinded crossover trial (MULTIWAVE study). Trials 21(1):696 
2. Courtney P, Espinet A, Mitchell B, Russo M, Muir A, Verrills P, Davis K (2015) Improved pain relief with burst spinal cord stimulation for two weeks in patients using tonic stimulation: results from a small clinical study. Neuromodulation 18(5):361-366

3. De Ridder D, Vanneste S, Plazier M, van der Loo E, Menovsky T (2010) Burst spinal cord stimulationtoward paresthesia-free pain suppression. Neurosurgery 66(5):986-990

4. Haider N, Ligham D, Quave B et al (2018) Spinal cord stimulation (SCS) trial outcomes after conversion to a multiple waveform SCS system. Neuromodulation 21(5):504-507

5. Kapural L, Yu C, Doust MW et al (2015) Novel 10-kHz highfrequency therapy (HF10 therapy) is superior to traditional lowfrequency spinal cord stimulation for the treatment of chronic back and leg pain: the SENZA-RCT randomized controlled trial. Anesthesiology 123(4):851-860

6. Metzger CS, Hammond MB, Pyles ST, Washabaugh EP, Waghmarae R, Berg AP, North JM, Pei Y, Jain R (2020) Pain relief outcomes using an SCS device capable of delivering combination therapy with advanced waveforms and field shapes. Expert Rev Med Devices 17(9):951-957

7. North J, Loudermilk E, Lee A et al (2020) Outcomes of a multicenter, prospective, crossover, randomized controlled trial evaluating subperception spinal cord stimulation at $\leq 12 \mathrm{kHz}$ in previously implanted subjects. Neuromodulation 23(1):102-108
8. Salmon J (2019) High-frequency spinal cord stimulation at 10 $\mathrm{kHz}$ for widespread pain: a retrospective survey of outcomes from combined cervical and thoracic electrode placements. Postgrad Med 131(3):230-238

9. Thomson SJ, Tavakkolizadeh M, Love-Jones S, Patel NK, Gu JW, Bains A, Doan Q, Moffitt M (2018) Effects of rate on analgesia in kilohertz frequency spinal cord stimulation: results of the PROCO randomized controlled trial. Neuromodulation 21(1):67-76

10. Vesper J, Slotty P, Schu S, Poeggel-Kraemer K, Littges H, Van Looy P, Agnesi F, Venkatesan L, Van Havenbergh T (2019) Burst SCS microdosing is as efficacious as standard burst SCS in treating chronic back and leg pain: results from a randomized controlled trial. Neuromodulation 22(2):190-193

Publisher's note Springer Nature remains neutral with regard to jurisdictional claims in published maps and institutional affiliations. 